\title{
Permitido decir "para": crítica de la perspectiva tradicional frente al problema de la teleología en la enseñanza de la biología
}

\author{
Permitted to say "for": criticism of the traditional perspective in the face of the \\ problem of teleology in the teaching of biology
Permitido dizer "por": crítica da perspectiva tradicional sobre o problema da teleologia no ensino da biología

Leonardo Martín González Galli

Recibido: octubre de 2018

Aceptado: diciembre de 2018

Para citar este artículo: González-Galli, L. M. (2019). Permitido decir "para": crítica de la perspectiva tradicional frente al problema de la teleología en la enseñanza de la biología. Revista Científica, 34(1), 49-62. Doi: https:// doi.org/10.14483/23448350.13710

\section{Resumen}

En este trabajo se reseña el problema de las concepciones teleológicas en la enseñanza y el aprendizaje de la biología evolutiva. Caracterizamos lo que denominamos la "perspectiva tradicional" en relación con este problema y cuestionamos los supuestos epistemológicos y psicológico-didácticos en que se basa. Contra dicha perspectiva tradicional, basada en el objetivo de eliminación del razonamiento teleológico y la censura de sus expresiones, ofrecemos una perspectiva alternativa basada en el desarrollo, por parte de los estudiantes, de la capacidad de regular consciente e intencionalmente el recurso a los razonamientos y expresiones teleológicas. Ofrecemos también algunos lineamientos para el diseño de actividades educativas concretas en relación con dicho objetivo.

Palabras clave: biología evolutiva, enseñanza, metacognición, selección natural, teleología.

\begin{abstract}
In this paper we review the problem of teleological conceptions in the teaching and learning of evolutionary biology. We characterize what we call the "traditional perspective" in relation to this problem and question the epistemological and psychological-didactic assumptions on which it is based. Against this traditional perspective, based on the objective of eliminating teleological reasoning and the censorship of their expressions, we offer an alternative perspective based on the development, on the part of students, of the ability to regulate consciously and intentionally the recourse to teleological reasoning and expressions. We also offer some guidelines for the design of specific teaching activities in relation to this objective.
\end{abstract}

Keywords: evolutionary biology, metacognition, natural selection, teaching, teleology. 


\section{Resumo}

Neste artigo, revisamos o problema das concepções teleológicas no ensino e aprendizagem da biologia evolutiva. Caracterizamos o que chamamos de "perspectiva tradicional" em relação a esse problema e questionamos os pressupostos epistemológicos e psicológico-didáticos nos quais ele se baseia. Contra essa perspectiva tradicional, baseada no objetivo de eliminar o raciocínio teleológico e a censura de suas expressões, oferecemos uma perspectiva alternativa baseada no desenvolvimento, por parte dos estudantes, da capacidade de regular, consciente e intencionalmente, o recurso ao raciocínio e à expressões teleológicas. Também oferecemos algumas diretrizes para o desenho de atividades educativas concretas em relação a esse objetivo.

Palavras-chaves: biologia evolutiva, seleção natural, teleologia, ensino, metacognição.

\section{Introducción}

La teoría de la evolución es un contenido central del currículo de Biología en la enseñanza general obligatoria. Esta importancia responde al lugar central que esta teoría ocupa en la Biología y a que, además, tiene profundas implicancias filosóficas, políticas y epistemológicas que exceden lo estrictamente biológico (Kampourakis, 2014; Stamos, 2009). A pesar de esta relevancia, numerosos estudios muestran que los resultados de la enseñanza de este tema están muy lejos de lo mínimamente aceptable (Smith, 2010). Este resultado se ha replicado en los más diversos países y en todos los niveles educativos desde hace unos 40 años. Entre los problemas detectados sobresale la existencia y persistencia de concepciones contradictorias con los modelos científicos aceptados, no solo en estudiantes de escuela media sino también en docentes, estudiantes y egresados de carreras universitarias afines a la Biología. A modo de ejemplo, Prinou, Halkia y Skordoulis (2008) reportan este fenómeno para el caso de Grecia; y González Galli y Meinardi (2017) para Argentina. Las creencias personales de los estudiantes y diversos factores sociales y culturales influyen en esta situación, por lo que es necesario intentar diferenciar dichos factores para concebir modos más adecuados de enseñanza (Bermúdez, 2015).

En relación con el problema de las concepciones de los estudiantes, las primeras investigaciones arrojaron un resultado - entre otros - que se ha replicado: los estudiantes presentan con frecuencia explicaciones teleológicas o finalistas (Settlage, 1994). En realidad, estas explicaciones no se restringen al tema "evolución"; los estudiantes las exhiben en muchos dominios de contenidos, especialmente en Biología (Kelemen, 1999). En este artículo analizo qué hacer, desde el punto de vista didáctico, con respecto a estas explicaciones teleológicas de los estudiantes. Para tal fin, caracterizaré la perspectiva más frecuente frente a este problema, que denominaré "tradicional", y la cuestionaré con base en análisis provenientes de la didáctica, la psicología cognitiva y la filosofía de la biología, para luego proponer una perspectiva diferente y, según creo, más adecuada para la enseñanza (González Galli, 2016a, 2016b).

\section{El problema de la teleología}

Las explicaciones teleológicas (o finalistas), en sentido amplio, son todas aquellas que incluyen la noción de fin, meta u objetivo (Gaeta et al., 1996). Omnipresente en el pensamiento Occidental, al menos desde Platón y Aristóteles, este tipo de explicaciones fueron cuestionadas con el advenimiento de la revolución científica (Allen, Bekoff y Lauder, 1998). Desde entonces, se asumió, en general, que la teleología no era científicamente aceptable por diversas razones. En primer lugar, porque implicaría supuestos sobrenaturales. En segundo lugar, porque parecería invertir la relación temporal causa-efecto $y$, finalmente, porque no se ajusta al patrón de explicación nomológico-deductivo ${ }^{2}$ (que alguna vez fue el ideal de las ciencias físicas).

\footnotetext{
Según el cual un fenómeno se considera explicado cuando su ocurrencia se infiere deductivamente a partir de ciertas leyes y condiciones iniciales.
} 
Sin embargo, a pesar de que la filosofía de la ciencia dominante, el positivismo lógico, posteriormente la "concepción heredada" y los propios científicos (por ejemplo, Futuyma, 2009) -influidos por dicha filosofía- decretaron su incorrección científica, las nociones y expresiones teleológicas nunca desaparecieron de la Biología (Rosenberg y McShea, 2008). De hecho, la noción de función, omnipresente en la Biología (tanto la "erudita" como la escolar), está estrechamente ligada a la teleología (McLaughlin, $2003)^{3}$. Esta persistencia fue entendida, desde posturas fisicalistas (es decir, que tomaban a la física clásica como el modelo de ciencia ideal), como un síntoma de la inmadurez de la biología como ciencia, un resabio de ideas precientíficas (Dennett, 2017). Así, se hicieron muchos intentos para eliminar las expresiones teleológicas y reemplazarlas por otras no teleológicas. Estos esfuerzos, sin embargo, resultaron infructuosos (Gaeta et al., 1996). Otros autores (por ejemplo, Ghiselin, 1994) han sugerido que los términos teleológicos que persisten en la Biología no son la expresión de verdaderos razonamientos finalistas, sino que se trata de un "modo de hablar" que, presuntamente, facilitaría el discurso o lo haría más comprensible para los no expertos. Dennett dice que los biólogos hacen referencia habitualmente a las funciones de los sistemas que estudian, pero que

[...] algunos biólogos y filósofos de la Biología se muestran incómodos con estas afirmaciones e insisten en que todas estas referencias a funciones $y$ propósitos son solo una forma de hablar, una metáfora útil, y que, estrictamente, no hay ninguna función, ningún propósito, ningún tipo de teleología en el mundo. (Dennett, 2017, p. 42)

\footnotetext{
La noción de función proviene de una analogía con los artefactos producto del diseño humano. Así, aquellas personas que crean que la teleología no debe estar presente en su discurso deberán renunciar a utilizar la noción de función. No se sugiere que tal cosa sea posible o deseable, sino más bien poniendo en evidencia lo ilusorio de la pretensión de purgar a la biología escolar de la teleología.
}

La experiencia personal, en el diálogo con biólogos y profesores de biología, sugiere que esta es la actitud dominante entre estos profesionales. No obstante, esta interpretación deja sin explicar algunas cuestiones notables: ipor qué la Biología es la única ciencia natural que encuentra conveniente este estilo discursivo?, ¿por qué, si se trata de simplificar el discurso para los no expertos, encontramos abundantes expresiones teleológicas aún en libros de texto universitarios?, ¿por qué no se suprimen totalmente estas expresiones dado el riesgo de que se las interprete erróneamente? Tenemos así una curiosa situación que algunos autores (Mahner y Bunge, 2000) han calificado de "esquizofrénica": los biólogos niegan la legitimidad de la teleología, pero no renuncian a ella. Existe entonces un debate abierto en la filosofía de la Biología en relación con la naturaleza y legitimidad de las nociones y expresiones teleológicas en la Biología. No es mi intención solucionar dicho debate sino más bien ofrecer una perspectiva útil para repensar el rol de la teleología en la enseñanza de la biología.

A continuación, se identifica la perspectiva más frecuente en el ámbito educativo en relación con este problema, para luego cuestionarla y ofrecer una alternativa que, creo, está mejor fundada desde el punto de vista epistemológico y psicológico-didáctico.

\section{La perspectiva tradicional frente al prob- lema de la teleología en la enseñanza}

Prácticamente toda la investigación sobre este tema ha supuesto que el carácter teleológico de las concepciones de los estudiantes es erróneo e indeseable. Véase, por ejemplo, Settlage (1994), y como notables excepciones Jungwirth (1975a, 1975b), Tamir y Zohar (1991) y Zohar y Ginossar (1998). Por lo tanto, el principal objetivo didáctico sería la eliminación del pensamiento teleológico. Peor aún, aquellos docentes que son conscientes de este problema suelen traducir esta perspectiva en una censura del lenguaje 
teleológico: "no se dice para" (Zohar y Ginossar, 1998). Esta perspectiva se basa en dos supuestos. El primero de estos es epistemológico y consiste en afirmar que los razonamientos teleológicos no tienen un lugar legítimo en la Biología actual. El segundo supuesto es psicológico-didáctico y consiste en afirmar que es posible (y deseable) que el estudiante abandone los razonamientos teleológicos en favor de otros (presuntamente) más respetables desde el punto de vista científico. Si se aceptan estos supuestos es claro que un buen aprendizaje de la Biología en general, y de la teoría de la evolución en particular, supondría renunciar totalmente a la teleología. Pero, como veremos, ambos supuestos son insostenibles a la luz de la investigación actual.

\section{Contra el primer supuesto de la perspectiva tradi- cional: hay teleología en la biología "erudita" actual}

A medida que se alejaba de los supuestos fisicalistas en que se basó en sus orígenes, la filosofía de la Biología tendió a reconocer la existencia y legitimidad de los razonamientos teleológicos en la Biología (Allen, 2003). Diversos autores han llevado a cabo análisis independientes que convergen en el reconocimiento de que los razonamientos teleológicos son una parte sustancial y no eliminable del modelo de evolución por selección natural (MESN) y, por lo tanto, de la Biología; al menos mientras este modelo ocupe un lugar central en dicha disciplina, como es el caso actual. A continuación, reseñaré brevemente los análisis de algunos de los autores que defienden que el MESN contiene supuestos teleológicos, pero perfectamente legítimos y respetables.

Para Caponi (2003), el MESN implica supuestos teleológicos porque las explicaciones construidas con base en dicho modelo se basan en el par categorial "problema-solución", que es intrínsecamente teleológico. Es decir, en una explicación darwiniana la prevalencia de una variante sobre las alterativas se explica identificando las razones (véase Dennett, 2017) por las cuales la variante seleccionada constituye una mejor solución a un determinado problema (evitar los depredadores, conseguir comida, etc.), y no identificando causas eficientes (físico-químicas) como sucede, por ejemplo, en las explicaciones de la fisiología.

Por su parte, Ruse (2000) sostiene que las expresiones y razonamientos teleológicos en Biología, y más específicamente en la Biología evolutiva darwiniana, son consecuencia del recurso a la metáfora del diseño. Esta metáfora consiste en analizar a los seres vivos o sus partes como si fueran objetos diseñados intencionalmente. Así, según Ruse, para construir una explicación darwiniana primero observamos el rasgo cuya evolución queremos explicar y nos preguntamos "ipara qué fue diseñado?", "¿para qué sirve?", “¿cuál es su función?" o "¿qué ventaja implica?". Cuando, a partir de esas preguntas, llegamos a alguna hipótesis razonable (por ejemplo, para evitar ser capturado por un depredador), construimos una explicación histórico-narrativa que parece no incluir ningún elemento teleológico pero que, y este es el punto importante, solo pudimos construir porque antes observamos al organismo como si fuera un objeto de diseño. Como se evidencia, según Ruse, la teleología responde a un razonamiento metafórico, se basa en la metáfora del diseño según la cual los organismos y sus partes son como objetos de diseño. Esto podría hacernos creer que, entonces, la teleología es eliminable, ya que podríamos limitarnos a usar expresiones estrictamente literales (si es que tal cosa fuera posible). Sin embargo, Ruse (2000) advierte que esta metáfora $-y$ la teleología que implica- es inevitable. Podemos utilizarla y luego pretender que no lo hicimos, como denuncia Ruse, pero no podemos no utilizarla.

Para dejar en claro que reconocer el rol de la teleología en la Biología no supone suscribir a supuestos sobrenaturales incompatibles con la ciencia, Ayala (1970; Dobzhansky et al., 1970) distingue distintas formas de teleología, entre ellas 
una que denomina "teleología natural indeterminada". Para este autor, la selección natural es un proceso teológico natural indeterminado porque explica la existencia de un rasgo identificando la contribución que este hace al mantenimiento del sistema (por eso es teleológico), no deriva de la acción de un agente intencional (por eso es natural) y su resultado final no es predecible (por eso es indeterminado).

Dennett $(1991,2017)$ por su parte sostiene que la comprensión de los seres vivos requiere adoptar lo que él denomina la actitud de diseño, un enfoque que supone analizar a los seres vivos como si fueran producto del diseño deliberado. Este enfoque está estrechamente ligado a la Ilamada "ingeniería reversa". Este autor considera que, de hecho, debemos reconocer que hay diseño en el mundo orgánico: "La biosfera está llena a rebosar de diseño, de propósito, de razones" (Dennett, 2017, p. 44). Dennett defiende un concepto naturalizado de diseño y de teleología que supone reconocer que en la naturaleza existe verdadero diseño como resultado del proceso, natural y no intencional, de selección natural.

Por razones de espacio no reseñaré los análisis de muchos otros autores (Brandon, 1981; Lennox, 1993; Lewens, 2000; Short, 2002; Walsh, 2000) que también sostienen que la teleología es parte sustancial, legítima y no eliminable de la teoría darwiniana. En línea con esta idea, y contra la frecuente afirmación (por ejemplo, Ghiselin, 1983: Mayr, 1992) de que Darwin eliminó la teleología de la biología, Sober (1996) y Dennett (2017), entre otros, señalan que, en realidad, la naturalizó. Es decir, la hizo científicamente respetable al ofrecer una explicación perfectamente naturalista del "diseño biológico".

Otros autores (entre ellos Monod, 1993; Mayr, 1998; Lorenz, 1986) prefirieron adoptar el término teleonomía. Aunque con este cambio buscaban evitar las polémicas connotaciones del término "teleología", está claro que se trata de un mero cambio terminológico que no logra escapar de la teleología (Hulswit, 1996). Estos autores definen teleonomía como la orientación a fines de un sistema debida a la operación de un programa que identifican con el genotipo del organismo. Como vemos, esta noción se basa en una metáfora (informática) que tiene tantas connotaciones teleológicas como la del diseño y que, en realidad, no es más que un caso particular de dicha metáfora. En efecto, los programas son secuencias de instrucciones construidas por un programador para cumplir una función predeterminada. Otros autores se ven obligados a acuñar extraños neologismos para dar cuenta del carácter teleológico de los seres vivos sin reconocerlo explícitamente, tal es el caso de Dawkins (1989), quien afirma que los seres vivos son "objetos diseñoides".

La conclusión de estos análisis es que, en la Biología actual, y más específicamente en los análisis adaptacionistas basados en el MESN, persisten argumentos teleológicos. Por ello, el lenguaje teleológico en la Biología no es únicamente un recurso retórico sino la expresión de un estilo de explicación propio del MESN. En relación con las objeciones antes mencionadas, estos razonamientos teleológicos no implican ningún supuesto sobrenatural, ni la inversión de la relación temporal causa-efecto (porque, de hecho, las explicaciones darwinianas no se basan en identificar causas eficientes, véase Caponi, 2003). Sí es posible que no se ajusten al modelo de explicación nomológico deductivo, pero ese no es un problema del darwinismo sino de dicho modelo de explicación, cuyas limitaciones ya han quedado claramente en evidencia (Gaeta et al., 1996). Para ser cauto, y aunque haya un consenso creciente en torno a estas conclusiones, se muestra el estatus polémico de la cuestión. En efecto, autores como Mahner y Bunge (2000) y Ghiselin (1983, 1994) continúan sosteniendo que no hay verdadera teleología en la Biología. Aun así, el primer supuesto que mencioné como base de la perspectiva tradicional en la enseñanza de la Biología debe ser revisado porque asume que no hay teleología legítima en la Biología sin siquiera reconocer el carácter polémico de tal afirmación. 


\section{Contra el segundo supuesto de la perspectiva tradicional: no es posible ni deseable eliminar el pensamiento teleológico de los estudiantes}

Veamos ahora el supuesto psicológico-didáctico según el cual es posible y deseable eliminar el razonamiento teleológico de los estudiantes. Numerosas investigaciones en psicología cognitiva (Inagaki y Hatano, 2006; Kelemen, 2012) sugieren que el sesgo teleológico es un rasgo central de una "biología intuitiva" que es parte de la cognición humana normal. Desde esta perspectiva (teoría de la modularidad), se sugiere que la mente humana consta de una serie de módulos que consisten en sistemas cognitivos especializados en el procesamiento de la información de dominios específicos (Hirschfeld y Gelman, 2002). Existe un fuerte consenso en cuanto a la existencia de una física y una psicología intuitivas; muchos autores (Inagaki y Hatano, 2006) sostienen que, además, existe una biología intuitiva autónoma ${ }^{4}$, uno de cuyos rasgos centrales es la teleología. Existen abrumadoras evidencias de que el pensamiento intuitivo sobre lo biológico se basa en gran medida en razonamientos teleológicos que tienen un gran poder predictivo y heurístico. En todos los contextos en los que se realizaron estudios se encontró el mencionado sesgo teleológico. Este sesgo, que parece operar ya desde los primeros meses de vida, restringe su alcance a medida que progresa el desarrollo y, sobre todo, con la instrucción formal; pero persiste, aún en el caso de adultos instruidos, cuando el sujeto analiza sistemas biológicos (Kelemen, 1999).

Lo dicho en el párrafo anterior implica que la eliminación del sesgo cognitivo teleológico no es factible ni deseable. En efecto, en caso de tener éxito con semejante "cirugía cognitiva" estaríamos privando al estudiante de un recurso indispensable para la vida. Podría argumentarse que lo que

Otros autores (Carey, 1995) creen que no existe una biología intuitiva autónoma, sino que la biología intuitiva deriva de la extensión de la psicología intuitiva (con todos sus sesgos teleológicos e intencionales) al dominio de lo biológico, pero este debate no afecta mis argumentos. se busca no es la eliminación total del sesgo teleológico, sino que dicho sesgo no se aplique cuando se trata de analizar los seres vivos y, más específicamente, cuando se trata de explicar su evolución. Pero, ¿por qué privar a los estudiantes de un recurso cognitivo que, de acuerdo con los análisis expuestos en el apartado anterior, resulta esencial para el razonamiento de los biólogos profesionales? Es decir, no es que los biólogos no recurren a la teleología, sino que "lo hacen bien", por lo que nuestro objetivo debería ser que los estudiantes también logren "hacerlo bien", y no que no lo hagan. "Hacerlo bien" significa saber cuándo corresponde y es útil recurrir a este tipo de razonamiento y saber exactamente qué significan (y qué no) las expresiones teleológicas utilizadas. Es decir, saber qué quieren decir al utilizar frases como "las plumas evolucionaron inicialmente para la termorregulación". En el apartado siguiente ofreceré algunas pistas sobre cómo lograr este objetivo. Se concluye en este apartado rechazando el segundo supuesto que sirve de base a la perspectiva tradicional.

\section{Una perspectiva alternativa}

Contra la perspectiva tradicional propondré un enfoque basado en el objetivo principal del desarroIlo, por parte de los estudiantes, de una capacidad de regulación consciente, en vez de en su eliminación, del sesgo cognitivo teleológico. Me referiré a esta capacidad como una "vigilancia metacognitiva" (Pérez, Gómez Galindo y González Galli, 2018). Aunque no existe una estrategia única para alcanzar este objetivo, un concepto clave en esta propuesta es el de metacognición (Zohar y Dori, 2012). El objetivo general que acabo de enunciar encierra, en realidad, varios objetivos específicos, entre ellos, que el o la estudiante: (1) sepa en qué consiste un razonamiento teleológico, (2) sepa reconocer un razonamiento de ese tipo y (3) pueda decidir conscientemente, en función de sus objetivos cognitivos y el contexto, cuándo puede utilizar un razonamiento teleológico y cuándo no y, 
en el primer caso, cómo hacerlo. Debo destacar que, en el caso que nos ocupa, es importante que al momento de regular el recurso y el uso de razonamientos y expresiones teleológicas el estudiante tenga como referencia teórica al MESN. Es decir, en el caso de la Biología, el estudiante debería basarse en el MESN para decidir y argumentar por qué determinadas explicaciones o expresiones por él o ella construidos son (o no) aceptables desde el punto de vista científico.

Volviendo a la cuestión de cómo acercarnos al logro de estos objetivos, sugiero que el marco teórico de los obstáculos epistemológicos (Astolfi, 2001; Camilloni, 2000) es especialmente adecuado para pensar cómo tratar didácticamente este problema (González-Galli y Meinardi, 2011). Por "obstáculo" entiendo formas de pensar que cumplen con tres condiciones. En primer lugar, son transversales, esto es, tienen cierto grado de generalidad, por lo que se expresan en relación con diversos tópicos. En segundo lugar, son funcionales, es decir, tienen poder predictivo, explicativo y heurístico para el sujeto. Esto es independiente de que estas formas de pensar se consideren o no científicamente correctas. En tercer lugar, son conflictivas desde el punto de vista educativo, en el sentido de que pueden interferir, de algún modo, en el aprendizaje de ciertos contenidos (González Galli, 2011; González Galli y Meinardi, 2016). Dada esta definición, el pensamiento teleológico sería un ejemplo paradigmático de obstáculo para el aprendizaje de la biología en general y de la teoría de la evolución en particular. Desde este marco teórico, en el que se asume que los obstáculos jamás desaparecen, se sugieren formas de trabajar que tienen el objetivo de que los estudiantes desarrollen la capacidad metacognitiva de "vigilar" el obstáculo. El trabajo didáctico sobre los obstáculos supone (1) la desestabilización, que no se refiere a la eliminación sino a la toma de conciencia de sus limitaciones, del obstáculo; (2) la (re)construcción conceptual, esto es, la construcción de una perspectiva diferente; y (3) la identificación del obstáculo (Astolfi y Peterfalvi, 2001).
Un objetivo principal en este tipo de propuesta es, entonces, que los estudiantes tomen conciencia de que piensan con base en el obstáculo en cuestión. En relación con este objetivo caben todas las sugerencias que se hacen, en general, para favorecer la metacognición (Campanario, 2000); por ejemplo, modelizar los estilos de razonamiento y favorecer la explicitación del pensamiento. Más allá de estas estrategias generales, en la siguiente sección sugeriré algunas más específicas ligadas a la enseñanza del MESN.

\section{Algunas estrategias posibles}

Asumo que el lenguaje científico no es, como se pretende desde ciertas posturas cientificistas, unívoco, transparente y libre de ambigüedades. Por el contrario, numerosos términos utilizados por los científicos (por ejemplo, "adaptación") tienen múltiples significados. Por lo tanto, considero que debemos enseñar a los estudiantes a lidiar con esta ambigüedad. Por eso sugiero crear instancias para la explicitación de significados anclados al contexto; debería ser frecuente en las clases detenernos para plantear la pregunta "¿Qué queremos decir con...?". Estas instancias de explicitación pueden generarse de un modo espontáneo, pero también es posible (y deseable) diseñar actividades específicas para promover estas reflexiones. Por ejemplo, como una estrategia posible para favorecer el desarrollo de la "vigilancia metacognitiva" sobre la teleología para el caso del aprendizaje del MESN, se podría proponer a los estudiantes evaluar la "corrección", es decir, la coherencia con el MESN, de las siguientes expresiones:

a. Las bacterias desarrollaron, durante su evolución, nuevas variedades de enzimas para protegerse de la acción de los antibióticos.

b. Ciertas variedades de enzimas bacterianas evolucionaron porque sirven para proteger a las bacterias de la acción de los antibióticos.

c. Las bacterias fueron seleccionadas para resistir a los antibióticos. 
d. Las enzimas de las bacterias están diseñadas para protegerlas de la acción de los antibióticos.

e. Las bacterias necesitaban resistir al antibiótico para sobrevivir y por eso la evolución produjo una nueva enzima.

f. Las bacterias mutaron para hacerse resistentes a los antibióticos.

g. Las bacterias se dieron cuenta de que necesitaban otro tipo de enzima para resistir al antibiótico y, entonces, evolucionó una nueva enzima.

Desde la perspectiva tradicional, todas estas expresiones son incorrectas, ya que todas son claramente teleológicas. Desde la perspectiva alternativa que propongo (que reconoce que el MESN implica razonamientos teleológicos), se da, en cambio, que algunas de estas expresiones podrían ser aceptables, mientras que otras no lo serían de ningún modo. Concretamente, las expresiones (a), (b), (c), (d) y (e) podrían considerase compatibles con el MESN, mientras que (f) y (g) no podrían considerarse aceptables en ningún caso. Conviene insistir aquí en que la razón por la cual (f) y (g) no serían aceptables no es que son teleológicas, sino que son incompatibles con el MESN. En el caso (f) se ubica el nexo teleológico en el origen de la variante, en vez de en la razón por la cual dicha variante incrementó su frecuencia en la población (Caponi, 2003), lo que es incorrecto según el MESN. Es decir, es aceptable decir que una variante fue seleccionada para (Sober, 1996), pero no que surgió para, ya que las mutaciones que originan esas variantes son aleatorias. El caso (g), por su parte, supone intencionalidad, elemento ausente en el MESN. Es necesario reconocer, sin embargo, que las expresiones (a), (b), (c), (d) y (e) son lo suficientemente vagas y ambiguas como para dejar dudas acerca del razonamiento subyacente. Por

Entre ellos: Iglesias-Rodríguez, Olmos-Migueláñez, Torrecilla-Sánchez y Mena-Marcos (2014), Rodríguez, Migueláñez, Sánchez y Marco (2015), Salas, Barrera y Fuentes (2015) y López (2015) ejemplo, ¿La persona que dice que "las bacterias desarrollaron, durante su evolución, nuevas variedades de enzimas para protegerse de la acción de los antibióticos" está pensando -erróneamente- que algo o alguien dirigió consciente e intencionalmente el proceso evolutivo de modo de garantizar la supervivencia de las bacterias o está señalando — correctamente-cuál es la razón por la cual esas variantes incrementaron su frecuencia en la población?

Pero este problema no se soluciona censurando la expresión teleológica y, de hecho, esta censura solo contribuye a que el estudiante oculte su pensamiento, cuando lo que se necesita es justamente lo contrario; que lo explicite para poder regularlo. En cambio, sugiero la necesidad de pedir a esa persona que aclare qué quiso decir con esa expresión. Esta actividad pretende ilustrar cómo se puede generar la discusión explícita sobre qué usos de los términos teleológicos se considerarán aceptables en el contexto de la clase de Biología. Esta cuestión deberá consensuarse en cada contexto de clase específico. Es probable que al lector le resulte difícil acordar conmigo en que este tipo de expresiones sean aceptables. Sin embargo, es importante recordar que estas expresiones son utilizadas en abundancia por biólogos profesionales. Veamos, a modo de ejemplo, los siguientes casos: "Los ribosomas eucarióticos y procarióticos son muy similares en diseño y función" (Alberts et al., 1994, p. 231); "[...] Los animales deben estar provistos de lo necesario para enfrentarse a sus necesidades biológicas" y "[...] las estructuras construidas por el hombre y las que han evolucionado por selección natural tienen rasgos de diseño que responden a problemas planteados por fuerzas físicas básicas" (Kardong, 1999, p. 119); "Los coágulos no son estructuras permanentes. Al contrario, están diseñados para disolverse cuando se restaura la integridad estructural de las zonas dañadas" (Stryer, 1995, p. 257); "Una larga serie de alteraciones acumuladas adaptó el diseño orgánico de los vertebrados para la vida en tierra" (Hickman, Larson y Eisenhour, 2008, p. 543). 
Nótese que se trata, en todos los casos, de libros de texto universitarios que, incluso así, utilizan expresiones fuertemente teleológicas, incluyendo el término "diseño". ¿Cómo justificar la censura en los estudiantes de expresiones que son utilizadas con frecuencia por los expertos en la disciplina? Por eso, mi propuesta apunta a que el estudiante comprenda cabalmente qué implican (y qué no) esas expresiones y cuáles y por qué podrían considerarse aceptables.

Otra estrategia con un gran potencial, consiste en basarse en análisis como el de Ruse (2000) para trabajar explícitamente con los estudiantes la teleología como la expresión de la metáfora del diseño. Se puede, por ejemplo, analizar cómo el mismo Charles Darwin utilizó este lenguaje (Lennox, 1993) y cómo lo justificó y defendió frente a la crítica de algunos de sus contemporáneos (véase González Galli, 2016a, 2014). Este análisis tiene la virtud añadida de permitirnos discutir el rol de las metáforas en la ciencia (Bradie, 1999).

Otra posibilidad interesante es proponer a los estudiantes comparar artefactos producto del diseño humano con adaptaciones producto de la selección natural (Lewens, 2000), para discutir en qué se parecen (y en qué no) estos objetos y los procesos que les dieron origen (véase González Galli y Meinardi, 2011). Sobran casos notables para llevar a cabo este análisis comparativo, por ejemplo, la coraza de un armadillo y la armadura de un cabaIlero medieval, o el sistema de ecolocación de un murciélago y el de los sonares humanos.

\section{Conclusiones}

Desde hace ya unas cuatro décadas se reconoce que los estudiantes presentan concepciones erróneas y fuertemente resistentes al cambio, en relación con la evolución biológica. Se sabe también que la teleología es uno de los principales rasgos de esas concepciones. En el ámbito educativo domina una actitud, acrítica y poco fundamentada, de rechazo y censura en relación con toda forma de teleología. En este trabajo caractericé esta postura tradicional y cuestioné los supuestos en que se basa. Ofrecí también los fundamentos de una perspectiva alternativa centrada en el desarrollo, por parte de los y las estudiantes, de una "vigilancia metacognitiva" (Peterfalvi, 2001). Podríamos decir, a modo de síntesis, que aprender Biología, y más específicamente el MESN, no requiere renunciar a la teleología sino "dominarla", esto es, utilizarla de un modo consciente y regulado, tal como lo hacen los expertos en esta disciplina. Considero, además, que al reconocer los estudiantes que la Biología tiene formas de explicación distintivas se favorece la construcción de una imagen de ciencia más compleja.

Es necesario hacer tres aclaraciones. En primer lugar, asumir — como aquí hago- que la teleología es parte de la Biología, y más específicamente del MESN, no implica negar que los razonamientos teleológicos intuitivos de los estudiantes puedan dificultar el aprendizaje del MESN o de otros contenidos de Biología; de hecho, normalmente lo hacen. Sin embargo, considero que el problema no es en sí la naturaleza teleológica de estos razonamientos intuitivos sino más bien su carácter implícito, no consciente y no regulado. Así, al operar "desde las sombras", este sesgo teleológico induce la construcción de explicaciones erróneas. Sin embargo, la misma intuición, adecuadamente regulada, es una herramienta cognitiva indispensable para la construcción de correctas explicaciones darwinianas. De ahí que mi propuesta se centre en el desarrollo de las capacidades metacognitivas de los estudiantes. En segundo lugar, debe quedar claro que, de acuerdo con los autores que mencionados aquí, la teleología en la Biología está directamente ligada al MESN. Esto significa que la teleología sería legítima siempre que se esté realizando un análisis basado en dicho modelo. Así, por ejemplo, si se considera que la coloración de un insecto evolucionó por deriva genética no cabría, en ese caso, ninguna forma de teleología. No tendría justificación, en tal caso, decir, por ejemplo, que esa coloración evolucionó "porque sirve para...". 
En síntesis, los razonamientos y expresiones teleológicos solo caben cuando se realizan análisis adaptativos o funcionales basados en el MESN 5 . Esto implica, además, que esta cuestión es independiente del debate acerca del Ilamado "adaptacionismo" ${ }^{\prime \prime}$, ya que no estamos afirmando que todos los rasgos son adaptativos sino que en aquellos casos en que creamos que cabe una explicación adaptacionista estaremos recurriendo a razonamientos teleológicos. En tercer lugar, conviene recordar aquí, a riesgo de ser reiterativos, que este reconocimiento de la legitimidad de la teleología no implica ningún supuesto sobrenatural ni mucho menos una validación de doctrinas pseudocientíficas como el autodenominado "creacionismo científico" y, su más reciente versión, la "teoría del diseño inteligente". En efecto, aunque estas doctrinas reclaman para sí legitimidad científica son, claramente, perspectivas religiosas que no tienen lugar alguno en la ciencia actual (Dawkins, 2007; Kampourakis, 2014) y que, por lo tanto, tampoco deberían tenerlo en las clases de ciencias (Branch y Scott, 2009). El temor a favorecer la postura del "creacionismo científico", o de la "teoría del diseño inteligente", también influye en la reticencia de muchos biólogos (Richard Dawkins, entre ellos) y filósofos a reconocer la legitimidad de una teleología naturalizada (Dennett, 2017).

En relación con cómo trabajar estas cuestiones con los estudiantes he ofrecido algunos lineamientos generales y unos pocos ejemplos más concretos. En cualquier caso, mi principal objetivo fue poner en cuestión una perspectiva que considero poco consistente en relación con este problema,

5. En realidad, la teleología en la Biología está asociada a las nociones de función y adaptación. A su vez, estas nociones - sobre todo la primera - pueden o no estar asociadas al MESN. En efecto, existen definiciones etiológicas de función, y otras no-etiológicas, estando solo las primeras ligadas al MESN (Sterelny y Griffiths, 1999). Desarrollar estas cuestiones demandaría más espacio del disponible. En cualquier caso, lo que debe quedar claro es que solo algunas explicaciones biológicas serían en algún sentido teleológicas.

6. La crítica clásica al adaptacionismo se encuentra en Gould y Lewontin (1979) y puede verse una réplica a estos autores en Dennett (1995). y ofrecer algunas pistas para pensarlo desde otro punto de vista que, según creo, está mejor fundado. Este artículo es una invitación a repensar la naturaleza de la Biología y cómo la enseñamos. En este sentido, en relación con el rol que la metáfora del diseño cumple en el MESN, Ruse afirma que:

[...] en virtud de esa metáfora esencial, la lógica misma del pensamiento evolucionista difiere de la lógica de las ciencias físicas. Posiblemente, podamos librarnos de ella, pero solo mediante una cirugía radical pues, en tal caso, no tendríamos ya la teoría de la cual partimos. Ahora bien, ¿es necesaria semejante cirugía? El mundo viviente es distinto del mundo inanimado. Limitémonos a aceptar este hecho y admitir que exige explicaciones diferentes, ni mejores ni peores, sólo diferentes. No más. (Ruse, 2008, pp. 91 y 92)

Y en cuanto la cuestión didáctica ligada a este problema, acuerdo con lo dicho por Jungwirth cuando, en referencia a quienes sostienen la perspectiva tradicional, señala que:

Cuesta creer que los autores mencionados no estén al tanto del carácter controversial de sus afirmaciones, o que deliberadamente elijan ignorarlo. Si no están al tanto, sería más deseable que, como otros, omitan enteramente hacer referencia a la teleología y sus derivaciones. Si su actitud es deliberada, las implicancias son más serias, porque en tal caso estaría justificado el término 'adoctrinamiento'. (Jungwirth, 1975b)

Parafraseando a Zohar y Ginossar (1998), entiendo que la postura que aquí defiendo resultará algo "herética" a los ojos de muchos biólogos y profesores de Biología, y reconozco que el tema es complejo y que hay otros posibles puntos de vista. Pero es claro también que hay aspectos de la práctica educativa que están más dictados por la tradición que por la reflexión fundamentada. Así,

En inglés en el original, traducción mía. 
espero que este artículo motive el debate y la reflexión crítica, más allá de las conclusiones a las que arribe cada lector.

\section{Referencias}

Alberts, B., Bray, D., Lewis, J., Raff, M., Roberts, K. y Watson, J. (1994). Molecular Biology of the Cell. Nueva York: Garland Publishing.

Allen, C. (2003). Teleological notions in biology. En E. Zalta (ed.), The Stanford Encyclopedia of Philosophy. Recuperado de https://plato.stanford.edu/entries/teleology-biology/

Allen, C., Bekoff, M. y Lauder, G. (1998). Nature's purposes. Analyses of Function and Design in Biology. Cambridge, E.E U.U.: MIT Press.

Astolfi, J. (2001). Conceptos clave en la didáctica de las disciplinas. Sevilla, España: Díada.

Astolfi, J. y Peterfalvi, B. (2001). Estrategias para trabajar los obstáculos: dispositivos y resortes. En A. Camilloni (ed.), Los obstáculos epistemológicos en la enseñanza (pp. 191-223). Barcelona: Gedisa.

Ayala, F. (1970). Teleological explanations in evolutionary biology. Philosophy of Sciences, 37(1), 1-15. DOI: https://doi.org/10.1086/288276

Bermúdez G. (2015) Los orígenes de la biología como ciencia. El impacto de las teorías de evolución y las problemáticas asociadas a su enseñanza y aprendizaje. Revista Eureka sobre Enseñanza y Divulgación de las Ciencias, 12(1), 66-90. DOI: https://doi.org/10.25267/ Rev Eureka ensen divulg_cienc

Bradie, M. (1999). Science and metaphor. Biology and Philosophy, 14(2), 159-166. DOI: https:// doi.org/10.1023/A:1006601214943

Branch, G y Scott, E. (2009). Estratagemas del creacionismo. Investigación y Ciencia, 388, 74-81.

Brandon, R. (1981). Biological teleology: Questions and explications. Studies in History and Philosophy of Science, 12(2): 91-105. DOI: https://doi.org/10.1016/0039-3681(81)90015-7

Camilloni, A. (ed.) (2001). Los obstáculos epistemológicos en la enseñanza. Barcelona: Gedisa.
Campanario, J. (2000). El desarrollo de la metacognición en el aprendizaje de las ciencias: estrategias para el profesor y actividades orientadas al alumno. Enseñanza de las Ciencias: Revista de Investigación y Experiencias Didácticas, 18(3), 369-380.

Caponi, G. (2003). Darwin: entre Paley y Demócrito. História, Ciências, Saúde. Manguinhos, 10(3), 993-1023. DOI: http://dx.doi. org/10.1590/S0104-59702003000300010

Carey, S. (1995). On the origin of causal understanding. En D. Sperber, D. Premak y A. Premak (eds.), Causal Cognition: A Multidisciplinary Debate (pp. 268-308). Nueva York: Oxford University Press.

Dawkins, R. (1989). El relojero ciego. Barcelona: Labor.

Dawkins, R. (2007). El espejismo de Dios. Madrid: Espasa-Calpe.

Dennett, D. (1991). La actitud intencional. Barcelona: Gedisa.

Dennett, D. (1995). Darwin's dangerous idea: Evolution and the meanings of Life. Nueva York: Simon and Schuster.

Dennett, D. (2017). De las bacterias a Bach. La evolución de la mente. Barcelona: Pasado y Presente.

Dobzhansky, T., Ayala, F., Stebbins, G. y Valentine, J. (1980). Evolución. Barcelona: Omega.

Fodor, J. (1996). Peacocking. London Review of Books, 18(8), 19-20. Recuperado de http://www.Irb.co.uk/v18/n08/jerry-fodor/ peacocking

Futuyma, D. (2009). Evolution. Sunderland, Reino Unido: Sinauer.

Gaeta, R., Gentile, N., Lucero, S. y Robles, N. (1996). Modelos de explicación científica. Problemas epistemológicos de las ciencias naturales y sociales. Buenos Aires: Eudeba.

Ghiselin, M. (1983). El triunfo de Darwin. Madrid: Cátedra.

Ghiselin, M. (1994). Darwin's Language May Seem Telelological, but his Thinking is Another Matter. Biology and Philosophy, 9(4), 489-492. DOI: https://doi.org/10.1007/BF00850377 
González Galli, L. (2011). Obstáculos para el aprendizaje del modelo de evolución por selección natural (tesis doctoral). Facultad de Ciencias Exactas y Naturales. Universidad de Buenos Aires. Recuperado de http://digital.bl. fcen.uba.ar/gsdl-282/cgi-bin/library.cgi?a=d\&$\mathrm{c}=$ tesis\&d=Tesis 4961 GonzalezGalli

González Galli, L. (2014). "Darwin teleólogo" y "el eclipse del darwinismo": dos casos para repensar la historia del evolucionismo. En $\mathrm{M}$. Quintanilla Gatica, S. Daza Rosales y H. Cabrera Castillo (comp.), Historia y filosofía de la ciencia. Aportes para una 'nueva aula de ciencias', promotora de ciudadanía y valores (pp. 266-284). Santiago de Chile: Bellaterra. Sociedad Chilena de Didáctica, Historia y Filosofía de la Ciencia.

González Galli, L. (2016a). "En biología nada tiene sentido si no es a la luz de la teleología": implicancias del problema de la teleología para la enseñanza del modelo de evolución por selección natural. En N. Cuvi, E. Sevilla, R. Ruiz y M. Puig Samper (eds.), Evolucionismo en América y Europa. Antropología, biología, política y educación (pp. 491-504). Quito, Ecuador: Ediciones Doce Calles, Flacso Ecuador, Universidad Autónoma de México, Pontificia Universidad Católica de Ecuador.

González Galli, L. (2016b). El problema de la teleología y la metáfora del diseño en biología: cuestiones epistemológicas e implicancias didácticas. TED (Tecné, Episteme y Didaxis), 40, 149-173. DOI: http://dx.doi. org/10.17227/01203916.6151

González Galli, L. y Meinardi, E. (2016). Obstáculos para el aprendizaje del modelo de evolución por selección natural. En N. Cuvi, E. Sevilla, R. Ruiz y M. Puig Samper (eds.), Evolucionismo en América y Europa. Antropología, Biología, Política y Educación (pp. 463-476). Quito, Ecuador: Ediciones Doce Calles, Flacso Ecuador, Universidad Autónoma de México, Pontificia Universidad Católica de Ecuador.
González Galli, L. y Meinardi, E. (2017). Obstáculos para el aprendizaje del modelo de evolución por selección natural en estudiantes universitarios de biología. Revista Eureka sobre Enseñanza y Divulgación de las Ciencias, 14(3), 435-449. DOI: http://dx.doi. org/10.25267/Rev Eureka ensen divulg cienc.2017.v14.i3.03

Gould, S. y Lewontin, R. (1979). The spandrels of San Marco and the Panglossian paradigm: A critique of the adaptationist programme. Proceedings of the Royal Society of London B, 205(1161), 581-598. DOI: http://dx.doi. org/10.1098/rspb.1979.0086

Hickman, R., Larson, K. y Eisenhour, L. (2008). Principios integrales de zoología. Madrid: MacGraw-Hill.

Hirschfeld, L. y Gelman, S. (2002). Hacia una topografía de la mente: una introducción a la especificidad de dominio. En L. Hirschfeld y S. Gelman (comp.), Cartografía de la mente. La especificidad de dominio en la cognición y en la cultura. Vol. I. Orígenes, procesos y conceptos (pp. 23-70). Barcelona: Gedisa.

Hulswit, M. (1996). Teleology: a Peircean Critique of Ernst Mayr's Theory. Transactions of the Charles S Peirce Society, 32(2), 182-214.

Inagaki, K. y Hatano, G. (2006). Young Children's Conception of the Biological World. Current Direction of Psychological Science, 15(4), 177 181. DOI: https://doi.org/10.1080/10409289. $\underline{2016.1220772}$

Jungwirth, E. (1975a). Caveat mentor-Let the teacher beware! Research in Science Education, 5(1), 153-160. DOI: https://doi.org/10.1007/ BF02558620

Jungwirth, E. (1975b). The problem of teleology in Biology as a problem of Biology teacher education. Journal of Biological Education, 9(6), 243-246. DOI: https://doi.org/10.1080/00219 $\underline{266.1975 .9654037}$

Kampourakis, K. (2014). Understanding evolution. Nueva York: Cambridge University Press. DOI: https://doi.org/10.1017/CBO9781139542357 
Kardong, K. (1999). Vertebrados. Anatomía comparada, función, evolución. Madrid: MacGraw-Hill, Interamericana.

Kelemen, D. (1999). Function, goals and intention: children's teleological reasoning about objects. Trends in Cognitive Sciences, 3(12), 461-468. DOI: https://doi.org/10.1016/ S1364-6613(99)01402-3

Kelemen, D. (2012). Teleological minds: How natural intuitions about agency and purpose influence learning about evolution. En K. Rosengren, S. Brem, E. Evans y G. Sinatra (eds.), Evolution challenges. Integrating research and practice in teaching and learning about evolution (pp. 66-92). Oxford, Reino Unido: Oxford University Press.

Lennox, J. (1993). Darwin was a teleologist. Biology and Philosophy, 8(4), 409-421. DOI: https://doi.org/10.1007/BF00857687

Lewens, T. (2000). Function Talk and the Artefact Model. Studies in History and Philosophy of Biology and Biomedical Sciences, 31(1), 95-111. DOI: https://doi.org/10.1016/ S1369-8486(99)00040-0

Lorenz, K. (1986). Fundamentos de etología. Barcelona: Paidós.

Mahner, M. y Bunge, M. (2000). Fundamentos de biofilosofía. México D.F.: Siglo XXI.

Mayr, E. (1992). Una larga controversia: Darwin y el darwinismo. Barcelona: Crítica.

Mayr, E. (1998). Así es la biología. Madrid: Debate. McLaughlin, P. (2003). What Functions Explain. Functional Explanation and Self-Reproducing System. Cambridge, EE.U.U.: Cambridge University Press.

Monod, J. (1993). El azar y la necesidad. Barcelona: Tusquets.

Pérez, G., Gómez-Galindo, A. A. y González-Galli, L. (2018). Enseñanza de la evolución: fundamentos para el diseño de una propuesta didáctica basada en la modelización y la metacognición sobre los obstáculos epistemológicos. Revista Eureka sobre Enseñanza y Divulgación de las Ciencias,
15(2), 2102. DOI: https://doi.org/10.25267/ Rev Eureka ensen divulg cienc.2018.v15. $\underline{\mathrm{i} 2.2102}$

Peterfalvi, B. (2001). Identificación de los obstáculos por parte de los alumnos. En A. Camilloni (ed.), Los obstáculos epistemológicos en la enseñanza (pp. 127-168). Barcelona: Gedisa.

Prinou, L. Halkia, L. y Skordoulis, C. (2008). What Conceptions do Greek School Students Form about Biological Evolution? Evolution: Education and Outreach, 1(3), 312-317. DOI: https://doi.org/10.1007/s12052-008-0051-x

Rosenberg, A. y McShea, D. (2008). Philosophy of Biology. A Contemporary Introduction. Nueva York: Routledge.

Ruse, M. (2000). Teleology: Yesterday, Today, and Tomorrow? Studies in History and Philosophy of Biological \& Biomedical Sciences, 31(1), 213-232. DOI: https://doi.org/10.1016/ $\underline{\text { S1369-8486(99)00046-1 }}$

Ruse, M. (2008). Charles Darwin. BuenosAires: Katz. DOI: https://doi.org/10.1002/9781444301366

Settlage, J. (1994). Conceptions of Natural Selection: A Snapshot of the Sense-Making Process. Journal of Research in Science Teaching, 31(5), 449-457. DOI: https://doi.org/10.1002/ tea.3660310503

Short, T. (2002). Darwin's concept of final cause: neither new nor trivial. Biology and Philosophy, 17(3), 322-340. DOI: https://doi. org/10.1023/A:1020173708395

Smith, M. (2010). Current Status of Research in teaching and Learning Evolution: II. Pedagogical Issues. Science and Education, 19(48), 523-538. DOI: https://doi.org/10.1007/ s11191-009-9216-4

Sober, E. (1996). Filosofía de la biología. Madrid: Alianza.

Stamos, D. (2009). Evolución. Los grandes temas: sexo, raza, feminismo, religión y otras cuestiones. Barcelona: Biblioteca Buridán.

Sterelny, K. y Griffiths, P. (1999). Sex and Death. An Introduction to Philosophy of Biology. Chicago, EE.UU.: The University Chicago Press. 
Stryer, L. (1995). Bioquímica. Barcelona: Reverté. Tamir, P. y Zohar, A. (1991). Anthropomorphism and teleology in reasoning about biological phenomena. Science Education, 75(1), 57-67. DOI: https://doi.org/10.1002/sce.3730750106

Walsh, D. (2000). Chasing Shadows: Natural Selection and Adaptation. Studies in History and Philosophy of Sciences, 31(1), 135-153. DOI: https://doi.org/10.1016/ $\underline{\text { S1369-8486(99)00041-2 }}$
Zohar, A. y Dori, Y. (eds.) (2012). Metacognition in Science Education. Trends in Current Research. Dordretch, Holanda: Springer. DOI: https://doi.org/10.1007/978-94-007-2132-6

Zohar, A. y Ginossar, S. (1998). Lifting the taboo regarding teleology and anthropomorphism in biology. Education-Heretical Suggestions. Science Education, 82(6), 679-697. DOI: https://doi.org/10.1002/(SICI)1098-237X(19981 1)82:6<679::AID-SCE3>3.0.CO;2-E 